\title{
Intramedullary spinal epidermoid presenting after thoracic meningocele repair: case report
}

\author{
Bartosz T. Grobelny, MD, Howard L. Weiner, MD, and David H. Harter, MD \\ Department of Neurosurgery, New York University Langone Medical Center, New York, New York
}

A 4-year-old girl with a history of thoracic meningocele repair at the age of 3 months presented with progressive myelopathy. An intramedullary thoracic epidermoid was identified on MRI. The patient underwent excision of the epidermoid and subsequently returned to neurological baseline. This case illustrates the potential for delayed development of intraspinal epidermoid after initial repair of a simple meningocele.

http://thejns.org/doi/abs/10.3171/2014.12.PEDS14270

KEY WORDS epidermoid; intramedullary; meningocele; spine; oncology

$\mathrm{S}$ PINAL epidermoid tumors are rare and are usually associated with spinal occult or overt dysraphism, particularly dermal sinus tracts. We present the case of a 4-year-old child who developed an intramedullary thoracic epidermoid tumor 4 years after uncomplicated repair of a simple thoracic meningocele.

\section{Case Report}

History and Examination

The patient presented after birth with a noticeable closed, round, midline subcutaneous cystic mass slightly caudal to the apex of her thoracic kyphosis. There was no family history of neural tube defect, and no maternal diabetes. An MRI study of this region revealed a meningocele at the T-9 level extending to the thoracic dura mater (Fig. 1). No associated dermal sinus was identified on clinical examination, ultrasound, or MRI.

\section{First Operation and Postoperative Findings}

At 3 months of age the patient underwent resection and repair of the meningocele. At the time of initial repair, the meningocele was excised. A small stalk with its base at the dura was identified. This was truncated at the level of the dura and was primarily repaired with 5-0 PDS suture. The specimen was sent in one piece to pathology. Its examination was negative for any pathological processes indicative of tumor. Postoperatively no neurological, bowel, bladder, or orthopedic deformities or dysfunction were noted. The MRI study obtained at that time showed expected postoperative changes and no evidence of any tumor. The posterior surface of the spinal cord, however, was noted to be irregular. This was attributed to changes from potential release of tethering that had been present as a result of the meningocele (Fig. 2).

\section{Second Presentation and Examination}

At 4 years of age the patient presented with gait deterioration and urinary urgency. On neurological examination she had full strength in all muscle groups, except 3/5 on left foot dorsal and plantar flexion. She did not have any abnormalities on sensory examination. There were no abnormal reflexes. The MRI session was repeated; an intramedullary mass extending from T-7 to T-10 was noted (Fig. 3). The lesion appeared to have several cysts with extension to the dorsal surface of the spinal cord. It was T1 

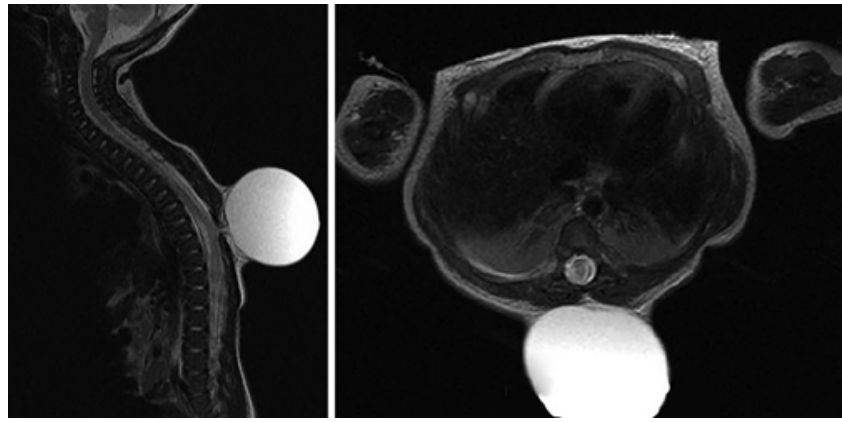

FIG. 1. Left: Sagittal T2-weighted MRI study of the spine showing the meningocele originating at the T-9 level. Right: Axial T2-weighted MRI study of the spine showing the meningocele and its stalk approaching the dura at the T-9 level.

hypointense, T2 hyperintense, and nonenhancing. There was an associated syrinx extending cranially to the midcervical spinal cord. No other lesions were noted on spinal imaging.

\section{Second Operation and Hospital Course}

The patient underwent a T7-10 laminectomy to expose the dura around the former meningocele tract. The tract was noted to follow intradurally. The dura was opened cranial and caudal to this tract, which was followed to the dorsal surface of the spinal cord. At the point of attachment to the cord we identified a pearly white intramedullary lesion. This subpial lesion could be followed cranially within the spinal cord. The tumor was debulked and dissected circumferentially by using a midline myelotomy to access the cranial extent. All tumor and capsule were successfully removed. Although there was fibrotic tissue that had to be divided to dissect the capsule from the cord, there was always a plane that allowed for the gross-total removal. Primary closure in layers was performed. Spinal cord monitoring was used in this case, and there were no changes in either motor or sensory signals after the resection.

\section{Postoperative Course}

The patient had an uneventful postoperative course, with discharge to home and subsequent complete resolution of her urological and gait dysfunction as well as of her left foot weakness by her 6-month follow-up. Pathological examination of the specimen yielded results consistent with epidermoid tumor. She has not undergone any subsequent imaging. We plan to follow her symptomatically to assess for future need of imaging studies.

\section{Discussion}

Spinal epidermoids are rare, comprising only $1.8 \%$ of all intramedullary tumors ${ }^{6}$ and $5 \%-17 \%$ of intramedullary tumors in pediatric series. ${ }^{2,5,12}$ They may occur with or without associated pathology (dysraphism or trauma) or by iatrogenic introduction during lumbar puncture., ${ }^{1,7}$ They may also occur after operative procedures for spinal fracture associated with CSF leakage ${ }^{10}$ and after operations for spinal dysraphism including repair of myelomeningocele, ${ }^{9}$

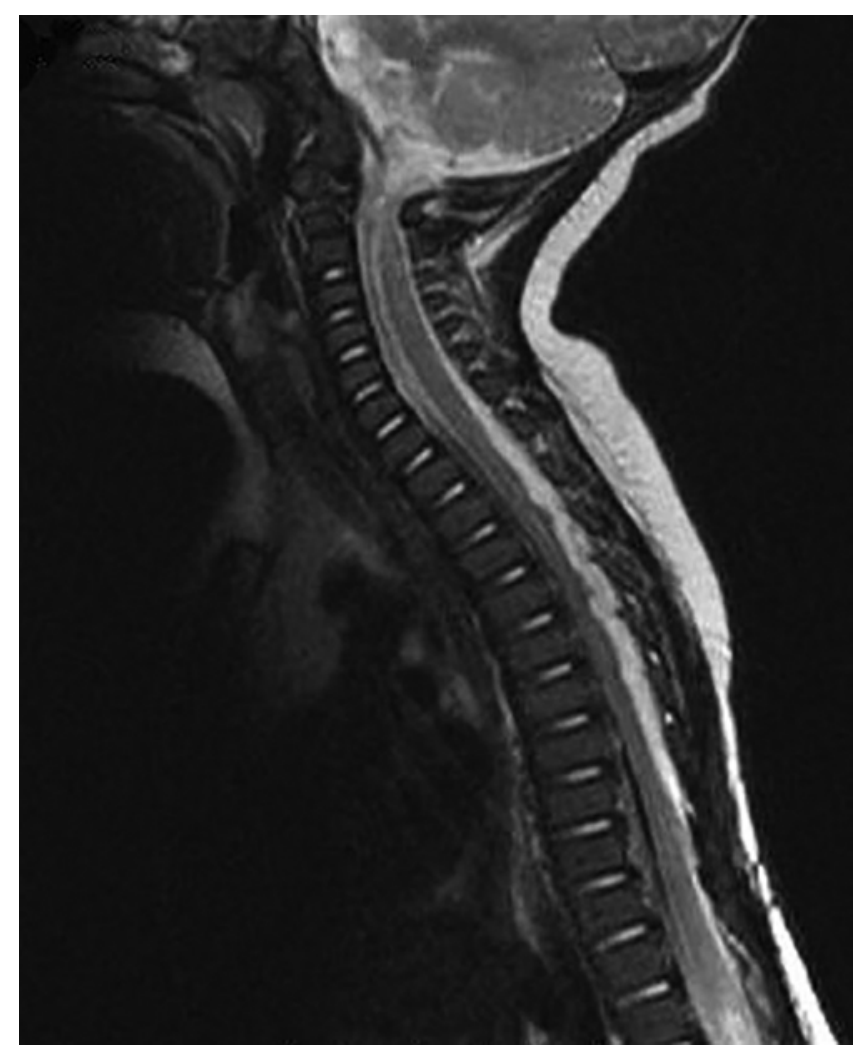

FIG. 2. Postoperative sagittal T2-weighted MRI study showing resection of meningocele and the now evident dorsal spinal cord irregularity, with no evidence of tumor.

lipomyelomeningocele, ${ }^{11}$ and (exceptionally) with meningocele,,$^{13}$ as in our patient.

Epidermoids diagnosed in patients with prior spinal surgery can be related to either iatrogenic introduction of cells or underlying present ectodermal rests, particularly with a diagnosed meningocele, which carries an association with dermoid/epidermoid tumors. ${ }^{3,8} \mathrm{~A}$ series of these by Scott et al. posits that dorsally located dermoids or epidermoids after myelomeningocele repair could be attributed to iatrogenic implantation of tissue, whereas the ventrally located tumors were a result of congenital dermal inclusions. ${ }^{9}$

Symptomatic epidermoids are treated surgically. These histologically benign ectodermal rests may recur locally. Given the rarity of spinal epidermoids, there is only sparse literature on recurrence. Lunardi et al. studied 8 patients with spinal epidermoids with 5-30 years of postsurgical follow-up and found no recurrence after their surgeries, although 2 of the 8 were already being treated for delayed (more than 10 years) recurrences. ${ }^{4}$

The lesion in our patient was dorsal and intramedullary. We were able to achieve a gross-total resection, both on visual inspection and as confirmed with postoperative MRI. Retrospectively, epidermoid was not identified on MRI studies performed prior to initial meningocele repair. It is likely that this lesion developed as a result of prior existing dermal inclusion elements, because the initial surgery did not explore the intradural space. It is possible 

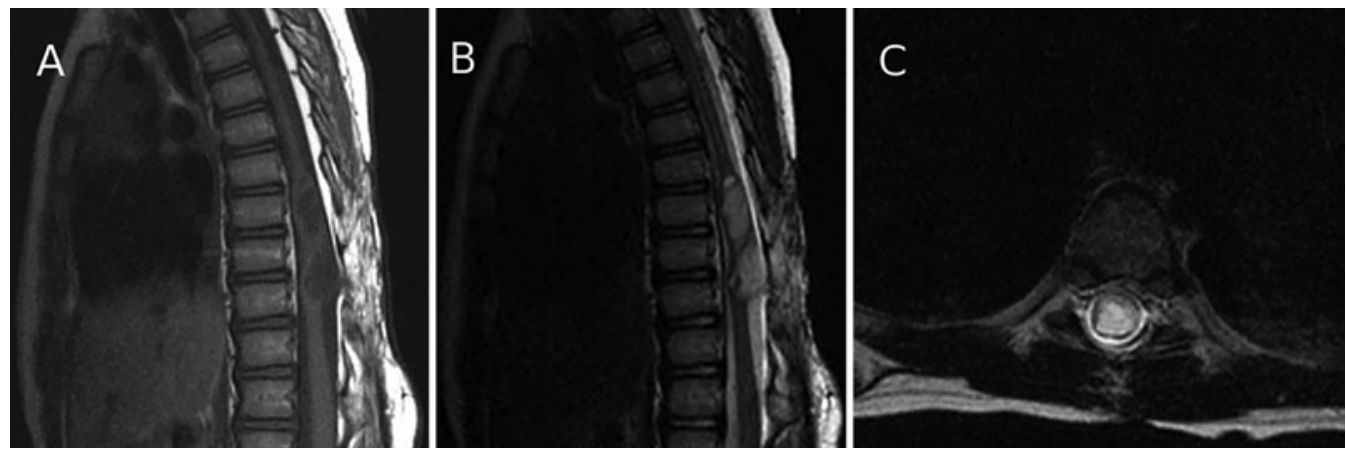

FIG. 3. A: Sagittal T1-weighted MRI study of the spine showing the extent of the intradural tumor. The part of the lesion at T-9 abuts the surface of the spinal cord, whereas the more cranial extent is entirely intramedullary. B: Sagittal T2-weighted MRI study of the same. C: Axial T2-weighted MRI study of the spine showing completely intramedullary tumor in a section through the T-8 level.

that with exploration of the intradural space during meningocele repair we would have been able to see and resect any apparent abnormal tissue, but it is difficult to say that our exposure would have been adequate if we were only exploring the level of the dysraphism.

\section{Conclusions}

This patient presented with an intramedullary spinal epidermoid tumor, probably as a result of the growth of dermal inclusion elements associated with her meningocele formation. The lesion was resected with no complication and she regained neurological function.

\section{References}

1. Choremis C, Economos D, Gargoulas A, Papadatos C: Intraspinal epidermoid tumours (cholesteatomas) in patients treated for tuberculous meningitis. Lancet 271:437-439, 1956

2. DeSousa AL, Kalsbeck JE, Mealey J Jr, Campbell RL, Hockey A: Intraspinal tumors in children. A review of 81 cases. J Neurosurg 51:437-445, 1979

3. Erşahin Y, Barçin E, Mutluer S: Is meningocele really an isolated lesion? Childs Nerv Syst 17:487-490, 2001

4. Lunardi P, Missori P, Gagliardi FM, Fortuna A: Long-term results of the surgical treatment of spinal dermoid and epidermoid tumors. Neurosurgery 25:860-864, 1989

5. Matson DD, Tachdjian MO: Intraspinal tumors in infants and children; review of 115 cases. Postgrad Med 34:279-285, 1963

6. Ogden AT, Khandji AG, McCormick PC, Kaiser MG: Intramedullary inclusion cysts of the cervicothoracic junction. Report of two cases in adults and review of the literature. $\mathbf{J}$ Neurosurg Spine 7:236-242, 2007

7. Park JC, Chung CK, Kim HJ: Iatrogenic spinal epidermoid tumor. A complication of spinal puncture in an adult. Clin Neurol Neurosurg 105:281-285, 2003

8. Sakai K, Sakamoto K, Kobayashi N, Iguchi H: Dermoid cyst within an upper thoracic meningocele. Surg Neurol 45:287292, 1996

9. Scott RM, Wolpert SM, Bartoshesky LE, Zimbler S, Klauber GT: Dermoid tumors occurring at the site of previous myelomeningocele repair. J Neurosurg 65:779-783, 1986

10. Sheng HS, Lin J, Wang HO, Yin B, Zhang N: Spinal epidermoid cyst formation after spinal fracture operation: a case report. Turk Neurosurg 23:800-802, 2013

11. Song JH, Kim MH, Shin KM: Intraspinal epidermoid cyst occurring 15 years after lipomyelomeningocele repair. Case report. J Neurosurg 90 (2 Suppl):252-254, 1999

12. Takeuchi J, Ohta T, Kajikawa H: Congenital tumors of the spinal cord, in Vinken P, Bruyn G (eds): Handbook of Clinical Neurology: Congenital Malformations of the Spine and Spinal Cord. Amsterdam: North-Holland, 1978, Vol 32, pp 355-392

13. Yen CP, Kung SS, Kwan AL, Howng SL, Wang CJ: Epidermoid cysts associated with thoracic meningocele. Acta Neurochir (Wien) 150:305-309, 2008

\section{Author Contributions}

Conception and design: Harter, Grobelny. Acquisition of data: Grobelny. Drafting the article: Grobelny. Critically revising the article: all authors. Reviewed submitted version of manuscript: all authors. Administrative/technical/material support: Harter, Weiner. Study supervision: Harter, Weiner.

\section{Correspondence}

David H. Harter, Department of Neurosurgery, New York University Langone Medical Center, 317 E. 34th St., Ste. 1002, New York, NY 10016. email: david.harter@nyumc.org. 